Revue d'histoire de l'Amérique française

REVUE D'HISTOIRE DE L'AMÉRIQUE FRANÇAISE

\title{
Société historique de la Vallée du Richelieu, Rapport de l'année 1964-65
}

\section{Émile Giroux}

Volume 19, numéro 2, septembre 1965

URI : https://id.erudit.org/iderudit/302487ar

DOI : https://doi.org/10.7202/302487ar

Aller au sommaire du numéro

Éditeur(s)

Institut d'histoire de l'Amérique française

ISSN

0035-2357 (imprimé)

1492-1383 (numérique)

Découvrir la revue

Citer ce document

Giroux, É. (1965). Société historique de la Vallée du Richelieu, Rapport de l'année 1964-65. Revue d'histoire de l'Amérique française, 19(2), 329-331. https://doi.org/10.7202/302487ar d'utilisation que vous pouvez consulter en ligne.

https://apropos.erudit.org/fr/usagers/politique-dutilisation/ 


\section{SOCIÉTÉS HISTORIQUES}

Faute de temps, quelques rapports de nos Sections n'ont pu être lus, à la réunion générale annuelle du 1er mai dernier. Nous continuons donc la publication de ces rapports.

\section{SOCIÉTÉ HISTORIQUE DE LA VALLÉE DU RICHELIEU}

\section{RAPPORT DE L'ANNÊE 1964-65}

L'adolescente Société Historique de la Vallée du Richelieu - elle n'a encore que 13 ans - a poursuivi vaillamment durant la présente année son travail commencé antérieurement.

Elle a d'abord voulu compléter ses structures en demandant au Secrétariat de la Province son incorporation officielle, ce qu'elle obtenait le 1er avril par l'octroi de lettres patentes. Souhaitons que cette reconnaissance publique lui facilite l'obtention de subventions nécessaires aux œuvres entreprises.

$\mathrm{Au}$ chapitre de ses activités mentionnons: quatre assemblées générales, soit au Musée Charles-Lemoyne de Longueuil, à VilleBrossard lors de l'érection d'une plaque historique en l'honneur du sulpicien martyr Guillaume Vignal, à Caughnawaga à l'occasion de son périple annuel en octobre et dernièrement au Collège Militaire Royal de Saint-Jean; de plus il y eut les réunions coutumières mensuelles du Bureau de direction.

Qu'est-il résulté de tout cela? Signalons parmi ses initiatives: l'assentiment de la Commission des Sites et Monuments Historiques à notre demande de pose d'une plaque commémorative sur l'emplacement de la maison natale de Sir Georges-E. Cartier à St-Antoine, en attendant qu'un musée y commémore de façon plus évidente la renommée du grand homme canadien; également le même assentiment donné à la pose de plaques sur les églises monuments historiques de L'Acadie et de SaintMathias.

Notre comité de toponymie a obtenu de la Commission de Géographie de Québec, ministère des Terres et Forêts, la substitution de deux noms de rivières locales, celui de la petite rivière 
de Montréal - appellation due sans doute à une déformation de l'expression "rivière des morelles" - qui est redevenue la "rivière de L'Acadie", nom qu'elle portait à l'origine; et celui de la "Montgomery Creek" près de St-Jean, nom dont les géographes anglais du Fédéral avaient baptisé le ruisseau Bernier qui a repris son nom originel et populaire.

Dans le domaine des recherches, en prévision du tricentenaire cette année des forts Sorel, Chambly et Ste-Thérèse, nous avons constitué le Comité du Fort Ste-Thérèse pour authentiquer l'emplacement contesté de cet ancien fort disparu. Des fouilles entreprises à notre demande par des archéologues du gouvernement provincial se sont avérées infructueuses. Cependant notre Comité, présidé par deux chercheurs chevronnés, notre archiviste M. Raymond Denault, et le R.P. Jules Romme, notre aumônier, après avoir recueilli plus de 25 plans de ce fort et dépouillé toute une chaîne d'actes notariés jusqu'en 1750, dont l'acte de vente par la veuve Hazen du territoire du fort, en est arrivé à la certitude morale que la fortification était bien établie à peu près à l'emplacement actuel du monument érigé par la Commission d'Ottawa.

Un autre de nos comités, celui du monument Louis Cyr, présidé par notre trésorier le Dr Gérald Aumont, petit-fils de l'homme fort canadien, a également continué ses démarches, en vue de l'érection prochaine d'un monument à la mémoire de ce héros de Napierville.

Parmi les publications que notre Société a encouragées, citons: la préparation de deux ouvrages, celui de Rosaire Benoît "Les Parents du Frère André de l'Oratoire" et le 2e tome de la monographie d'Iberville, par Mlle Yvonne Labelle, notre bibliothécaire; la parution récente du livre "Le Fort Saint-Jean, trois siècles d'histoire" œuvre du R.P. Jacques Castonguay, aumônier au Collège Militaire Royal et membre de notre Société; sans compter maintes études sur les forts de St-Jean, de Chambly et le blockhaus de Lacolle par M. Armand Thibodeau, notre viceprésident; les monographies de Rosaire Benoît sur l'histoire de Marieville et St-Grégoire, celle de Pierre Brault sur la rivière de l'Acadie, et de multiples articles sur les activités de notre Société parus dans les journaux locaux par les soins de notre secrétariat.

Il convient de noter que notre Président assumait en même temps la présidence du comité provisoire chargé d'élaborer la constitution de la nouvelle Fédération des Sociétés d'Histoire 
du Québec, et obtenait en mars dernier les lettres patentes de cette nouvelle Fédération.

Une initiative à ne pas oublier c'est la résolution que nous avons soumise au Ministère de l'Education relativement à l'usage des drapeaux dans les écoles. Au temps où l'on déplorait l'absence de drapeau dans nos institutions scolaires semble avoir succédé l'actuelle bataille des drapeaux dans certaines écoles. Voilà pourquoi notre Société a pris l'initiative de soumettre au Ministère de l'Education la proposition suivante: "que le fleurdelysé soit le premier drapeau en usage dans toutes les institutions scolaires du Québec et que, lorsqu'il sera arboré avec d'autres emblêmes nationaux, il soit toujours à la place d'honneur". Le Ministre accusant réception de notre proposition nous apprend qu'un comité chargé du protocole est à rédiger les directives à ce sujet.

Dirons-nous que les heures les plus heureuses de notre année paraissent bien avoir été celles de notre promenade historique annuelle qui eut lieu le dimanche 25 octobre: rencontre à Caughnawaga pour la messe dominicale d'une trentaine d'intéressés représentant quatre sociétés historiques régionales. Après l'office chanté par une chorale mixte indienne et la visite des lieux, l'on suivit le fleuve St-Laurent jusqu'à Contrecœur, avec arrêts à Boucherville, Varennes et Verchères, le souper étant pris à l'Auberge des Patriotes, à St-Antoine-sur-Richelieu.

Telles ont été quelques-unes des nobles occupations des membres de notre jeune société depuis notre dernier rapport annuel.

Frère Emile Giroux, F.M.S.,

Secrétaire.

(à suivre) 